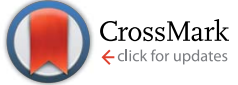

Cite this: RSC Adv., 2016, 6, 22896

Received 7th December 2015 Accepted 20th February 2016

DOI: 10.1039/c5ra26117a

www.rsc.org/advances

\section{The effects of light and temperature on microalgal growth and nutrient removal: an experimental and mathematical approach $\uparrow$}

\begin{abstract}
Ana L. Gonçalves, José C. M. Pires and Manuel Simões*
Cultivation of microalgae and cyanobacteria has been intensified in the last decades, due to the numerous applications described for these microorganisms. However, the high process costs associated with biomass production systems reduce the economic feasibility of microalgal/cyanobacterial cultivation. A better understanding of the effects of light and temperature on growth kinetics will contribute to the improvement of biomass productivities and reduce the costs associated with the optimization of culture parameters. In this study, the effects of average daily light irradiance and temperature on growth and nutrient removal were assessed using Chlorella vulgaris, Pseudokirchneriella subcapitata, Synechocystis salina and Microcystis aeruginosa. Additionally, a mathematical model relating specific growth rates with these variables was developed. Both kinetic growth parameters and nutrient removal had similar responses to light and temperature: increasing light supply, higher specific growth rates, biomass productivities and nutrient removal efficiencies were achieved. Among the studied temperatures, all microorganisms presented higher biomass productivities and nutrient removal efficiencies at $25^{\circ} \mathrm{C}$. Regarding the results from the mathematical model, the optimal temperature for the selected microorganisms was $25.3 \pm 1.1^{\circ} \mathrm{C}$. On the other hand, the optimal average daily light irradiances varied with the species, being 208, 258, 178 and $140 \mu \mathrm{E} \mathrm{m}^{-2} \mathrm{~s}^{-1}$ for C. vulgaris, P. subcapitata, S. salina and M. aeruginosa, respectively.
\end{abstract}

\section{Introduction}

Microalgae are a broad category of photosynthetic microorganisms, comprising single-cell eukaryotic microalgae and prokaryotic cyanobacteria. Cultivation of these photosynthetic microorganisms has gained much attention in the last decades, due to the huge potential of these microorganisms in such a variety of applications. When growing autotrophically, microalgae and cyanobacteria uptake $\mathrm{CO}_{2}$ from the atmosphere and/or flue gas emissions, reducing the concentration of this greenhouse gas in the atmosphere. ${ }^{1}$ Additionally, these microorganisms assimilate nitrogen and phosphorus, the main contributors to the eutrophication phenomenon, playing an important role in the remediation of water resources. ${ }^{2,3}$ Due to the rich composition of microalgal/cyanobacterial cells, their biomass can then be used in different applications, such as human food and animal feed, production of drugs, cosmetics, functional food, biofuels and fertilizers. ${ }^{4-7}$ Despite the numerous applications described for microalgae and cyanobacteria, cultivation of these microorganisms still presents some challenges regarding the

LEPABE, Departamento de Engenharia Quimica, Faculdade de Engenharia, Universidade do Porto, Rua Dr. Roberto Frias, 4200-465 Porto, Portugal. E-mail: mvs@fe.up.pt; Fax: +351 22508 1449; Tel: +351 225081654

$\dagger$ Electronic supplementary information (ESI) available. See DOI: 10.1039/c5ra26117a achievement of high biomass productivities at reduced costs. Accordingly, optimization of cultivation parameters in order to obtain an economically viable process with increased biomass productivities becomes necessary. Microalgal/cyanobacterial growth can be affected by several factors, both biotic and abiotic. Biotic factors include the presence of pathogens, such as bacteria, fungi and viruses, and the competition by other microalgae, whereas abiotic factors include light, temperature, $\mathrm{pH}$, salinity, nutrient qualitative and quantitative profiles, dissolved oxygen concentration and the presence of toxic compounds. Additionally, microalgal and cyanobacterial growth can be influenced by operational conditions, such as hydraulic residence time, harvesting rates, gas transfer and mixing. ${ }^{\mathbf{8 - 1 1}}$ Among these parameters, light supply and temperature appear as the most important factors influencing microalgal and cyanobacterial growth. In fact, photoautotrophic growth is driven by light supply, the energy source that is used to convert inorganic carbon into organic matter, and changes in temperature can easily affect microalgal/cyanobacterial growth since the metabolic activity of these photosynthetic microorganisms can be ceased by extreme temperatures. Furthermore, interaction between these variables in outdoor cultures determines the biochemical profile of the resulting biomass and growth state. ${ }^{\mathbf{1 2}}$

In this study, the effects of light supply (average daily light irradiance) and temperature on biomass production and nutrient uptake were assessed for the microalgae Chlorella 
vulgaris and Pseudokirchneriella subcapitata and the cyanobacteria Synechocystis salina and Microcystis aeruginosa. Selection of these microorganisms was based on the following factors: ${ }^{13-16}$ (i) these microalgae and cyanobacteria can be easily grown in laboratory cultures; and (ii) several authors have reported the use of these microorganisms in a wide variety of biotechnological applications, such as $\mathrm{CO}_{2}$ capture, wastewater treatment, biofuels production and synthesis of bioactive compounds. Additionally, due to the wide diversity of microalgal and cyanobacterial species, the study and optimization of culture parameters for all these microorganisms under different light and temperature conditions is very difficult. In this sense, mathematical modelling of these variables constitutes an important tool for growth prediction and characterization. Mathematical models describing the effect of light supply and temperature on microalgal/cyanobacterial growth have already been reported in the literature. ${ }^{17-20}$ However, only a few studies have considered both variables simultaneously. ${ }^{21-23}$ Accordingly, a kinetic growth model was developed to determine optimal light and temperature conditions for the selected microorganisms.

\section{Materials and methods}

\subsection{Microorganisms and culture medium}

The microalgae C. vulgaris CCAP 211/11B and P. subcapitata CCAP 278/4 were obtained from Culture Collection of Algae and Protozoa (United Kingdom), while the cyanobacteria S. salina LEGE 06079 and M. aeruginosa LEGE 91344 were obtained from the Laboratory of Ecotoxicology, Genomic and Evolution - CIIMAR (Centre of Marine and Environmental Research of the University of Porto, Portugal). Stock solutions of these microorganisms were prepared in OECD (Organisation for Economic Co-operation and Development) test medium, ${ }^{24}$ with the following composition (per litre): $15 \mathrm{mg} \mathrm{NaNO}_{3}, 12 \mathrm{mg} \mathrm{\textrm {MgCl } _ { 2 } -}$ $\cdot 6 \mathrm{H}_{2} \mathrm{O}, 18 \mathrm{mg} \mathrm{CaCl}_{2} \cdot 2 \mathrm{H}_{2} \mathrm{O}, 15 \mathrm{mg} \mathrm{MgSO}_{4} \cdot 7 \mathrm{H}_{2} \mathrm{O}, 1.6 \mathrm{mg}$ $\mathrm{KH}_{2} \mathrm{PO}_{4}, 0.08 \mathrm{mg} \mathrm{FeCl} \cdot 6 \mathrm{H}_{2} \mathrm{O}, 0.1 \mathrm{mg} \mathrm{Na} 2$ EDTA $2 \mathrm{H}_{2} \mathrm{O}, 0.185$

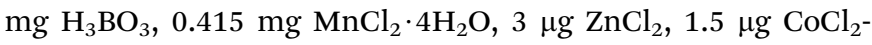
$\cdot 6 \mathrm{H}_{2} \mathrm{O}, 0.01 \mu \mathrm{g} \mathrm{CuCl} \cdot 2 \mathrm{H}_{2} \mathrm{O}, 7 \mu \mathrm{g} \mathrm{Na}_{2} \mathrm{MoO}_{4} \cdot 2 \mathrm{H}_{2} \mathrm{O}$ and $50 \mathrm{mg}$ $\mathrm{NaHCO}_{3}$. The cells were incubated in $500 \mathrm{~mL}$ flasks at room temperature, under continuous fluorescent light with an irradiance of $120 \mu \mathrm{E} \mathrm{m}^{-2} \mathrm{~s}^{-1}$ (corresponding average daily light irradiance is $120 \mu \mathrm{E} \mathrm{m}^{-2} \mathrm{~s}^{-1}$ ) at the surface of the flasks. Agitation was obtained by bubbling atmospheric air (filtered through $0.22 \mu \mathrm{m}$ cellulose acetate membranes, Orange Scientific, Belgium) at the bottom of the flasks.

\subsection{Experimental setup and cultivation conditions}

Batch experiments were performed in $500 \mathrm{~mL}$ flasks (VWR, Portugal) with a working volume of $400 \mathrm{~mL}$. As the growth medium described above presents a very low concentration of nitrogen and phosphorus, concentrations of these elements were increased to simulate the concentrations commonly present in a secondary treated effluent. Therefore, cells were cultivated for 12 days in the culture medium described above, but with the following concentrations of $\mathrm{NaNO}_{3}$ and $\mathrm{KH}_{2} \mathrm{PO}_{4}: 250$ and $45 \mathrm{mg}$
$\mathrm{L}^{-1}$, respectively. ${ }^{25}$ In this study, nitrate was used as nitrogen source because this is the most thermodynamically stable form of inorganic nitrogen ${ }^{8}$ and also because it is the most abundant nitrogen form in the tertiary treatment step of wastewater treatment plants, where microalgae can play an important remediation role. ${ }^{25}$ The experimental conditions were the following: (i) initial cell concentration of approximately $1.0 \times 10^{6}$ cells per $\mathrm{mL}$, which corresponds to a biomass (cell dry weight - dw) concentration of about $0.05-0.08 \mathrm{~g}_{\mathrm{dw}} \mathrm{L}^{-1}$; (ii) initial $\mathrm{pH}$ was set at 7; (iii) continuous aeration with the injection of atmospheric air (filtered through $0.22 \mu \mathrm{m}$ cellulose acetate membranes, Orange Scientific, Belgium) at the bottom of the flasks. The assays were carried out under different temperatures $\left(15,25\right.$ and $\left.35^{\circ} \mathrm{C}\right)$ and incident light irradiances ( 36 and $180 \mu \mathrm{E} \mathrm{m}^{-2} \mathrm{~s}^{-1}$ ). The temperatures of 15,25 and $35{ }^{\circ} \mathrm{C}$ were selected to simulate average temperatures observed in cold, warm and tropical regions, respectively. Light irradiance values were selected to observe the effect of low and high irradiance levels. Selection of this specific range of light irradiance values has taken into account the possible values that can be achieved using artificial light. For each temperature and irradiance value, different light cycles were evaluated: $10: 14$, $14: 10$, and $24: 0$ (light : dark ratio). The light: dark ratio of $24: 0$ was used because it promotes continuous photoautotrophic growth. To reduce production costs in terms of light requirements, the light : dark ratios of $10: 14$ and $14: 10$ were applied to simulate the number of light hours during winter and summer time, respectively. For each studied condition, two independent experiments were performed. Taking into account the light irradiances and light: dark ratios evaluated in this study, the corresponding average daily light irradiances are presented in Table 1.

\subsection{Growth monitoring and kinetic growth parameters}

Duplicate samples were collected at $24 \mathrm{~h}$ intervals and biomass concentration was determined by measuring optical density at $750 \mathrm{~nm}, \mathrm{OD}_{750},{ }^{26}$ using a V-1200 spectrophotometer (VWR, Portugal). The relationship between $\mathrm{OD}_{750}$ and biomass concentration $\left(X, \mathrm{mg}_{\mathrm{dw}} \mathrm{L}^{-1}\right)$ for all microorganisms was established by linear regression, using the previously determined expressions. $^{27}$ Biomass concentration values were used to determine specific growth rates $\left(\mu, \mathrm{d}^{-1}\right)$ and biomass productivities $\left(P, \mathrm{mg}_{\mathrm{dw}} \mathrm{L}^{-1} \mathrm{~d}^{-1}\right)$. Specific growth rates were determined according to eqn (1): $:^{28}$

Table 1 Average daily light irradiances evaluated in this study considering light irradiance and light : dark ratio values applied to the selected cultures

\begin{tabular}{lll}
\hline $\begin{array}{l}\text { Light irradiance } \\
\left(\mu \mathrm{E} \mathrm{m}^{-2} \mathrm{~s}^{-1}\right)\end{array}$ & $\begin{array}{l}\text { Light }: \text { dark } \\
\text { ratio }(\mathrm{h}: \mathrm{h})\end{array}$ & $\begin{array}{l}\text { Average daily light irradiance } \\
\left(\mu \mathrm{E} \mathrm{m} \mathrm{m}^{-2} \mathrm{~s}^{-1}\right)\end{array}$ \\
\hline 36 & $10: 14$ & 15 \\
& $14: 10$ & 21 \\
& $24: 0$ & 36 \\
180 & $10: 14$ & 75 \\
& $14: 10$ & 105 \\
& $24: 0$ & 180
\end{tabular}




$$
\mu=\frac{\ln X_{2}-\ln X_{1}}{t_{2}-t_{1}}
$$

where $X_{2}$ and $X_{1}$ correspond to biomass concentration (in $\mathrm{mg}_{\mathrm{dw}}$ $\mathrm{L}^{-1}$ ) at times $t_{2}$ and $t_{1}$ (in days), the end and beginning of the exponential growth phase, respectively. Biomass productivities achieved in the exponential growth phase were calculated from the variation in biomass concentration within the exponential growth phase, as shown in eqn (2): ${ }^{28,29}$

$$
P=\frac{X_{2}-X_{1}}{t_{2}-t_{1}}
$$

\subsection{Nutrients removal}

Nutrients removal was determined by quantification of nitrogen and phosphorus in the culture medium. For each analytical assay, one-millilitre samples from each culture were collected in the first and last day of culturing. Samples were centrifuged at $16500 \mathrm{~g}$ for $10 \mathrm{~min}$ and supernatants were stored at $-20^{\circ} \mathrm{C}$ until being analysed. Nitrate concentration was determined through UV spectroscopy at $220 \mathrm{~nm}$ using a T80 UV/VIS Spectrophotometer (PG Instruments, UK), according to the method proposed by Collos et al. ${ }^{30}$ On the other hand, inorganic phosphate quantification was performed by measuring absorbance at $820 \mathrm{~nm}$ of a phosphomolybdate complex formed by reaction of inorganic phosphate with ammonium molybdate in a Synergy $^{\text {TM }}$ HT 96-well microplate reader (Biotek Instruments, Inc., USA), as proposed by Lee et al. ${ }^{31}$ Nutrients concentration in the first and last day of culturing were used to determine average removal rates (RR, in $\mathrm{mg}_{\mathrm{S}} \mathrm{L}^{-1} \mathrm{~d}^{-1}$ ) and nutrients removal efficiencies $(R$, in \%). Average removal rates were calculated as follows: ${ }^{32}$

$$
\mathrm{RR}=\frac{S_{\mathrm{f}}-S_{\mathrm{i}}}{t_{\mathrm{f}}-t_{\mathrm{i}}}
$$

where $S_{\mathrm{f}}$ and $S_{\mathrm{i}}$ correspond to nutrients concentration (in $\mathrm{mg}_{\mathrm{s}}$ $\mathrm{L}^{-1}$ ) at times $t_{\mathrm{f}}$ and $t_{\mathrm{i}}$ (in days), the end and beginning of cultivation time, respectively. Nutrients removal efficiencies were determined according to eqn (4):

$$
\% R=\frac{S_{\mathrm{i}}-S_{\mathrm{f}}}{S_{\mathrm{i}}} \times 100
$$

Additionally, for each nutrient a mass balance was written and the mass fractions $\left(\alpha\right.$, in $\left.\mathrm{g}_{\mathrm{s}} \mathrm{g}_{\mathrm{dw}}{ }^{-1}\right)$ of nitrogen and phosphorus incorporated in microalgal/cyanobacterial biomass were determined. This mass balance was determined according to eqn (5): ${ }^{33}$

$$
\frac{\mathrm{d} S}{\mathrm{~d} t}=-\alpha \frac{\mathrm{d} X}{\mathrm{~d} t}
$$

where $S$ corresponds to nutrients concentration (in $\mathrm{g}_{\mathrm{S}} \mathrm{L}^{-1}$ ). By integrating eqn (5) over the cultivation time, eqn (6) was obtained:

$$
\left(S_{\mathrm{i}}-S_{\mathrm{f}}\right)=\alpha\left(X_{\mathrm{f}}-X_{\mathrm{i}}\right)
$$

\subsection{Modelling of microalgal growth}

To determine the optimal growth conditions (average daily light irradiance and temperature) for the selected microalgae and cyanobacteria, a kinetic growth model was developed. Development of this model was based on specific growth rates determined for each of the studied microorganisms when grown under different light and temperature conditions. These data were obtained in this study and in other studies reported in the literature, as it is possible to see in Table S1 from the ESI. $\dagger$

The behaviour of specific growth rates for increasing average daily light irradiance values was described according to the model proposed by Steele: ${ }^{20}$

$$
\mu=\frac{\mu_{\mathrm{max}} I}{I_{\mathrm{opt}}} \mathrm{e}^{\left(1-\frac{I}{I_{\mathrm{opt}}}\right)}
$$

where $\mu_{\max }$ corresponds to the maximum specific growth rate (in $\mathrm{d}^{-1}$ ) achieved by the studied microorganisms, $I$ denotes average daily light irradiance (in $\mu \mathrm{E} \mathrm{m}^{-2} \mathrm{~s}^{-1}$ ) and $I_{\mathrm{opt}}$ corresponds to the optimal value of average daily light irradiance (in $\mu \mathrm{E} \mathrm{m}^{-2} \mathrm{~s}^{-1}$ ) for microalgal/cyanobacterial growth.

On the other hand, the behaviour of specific growth rates for different temperatures was assumed to follow a skewed normal distribution, as reported by Dauta et al.: ${ }^{34}$

$$
\mu=\mu_{\max } \mathrm{e}^{-\frac{\left(T-T_{\mathrm{opt}}\right)^{2}}{2 \sigma^{2}}}
$$

where $T$ is the temperature (in ${ }^{\circ} \mathrm{C}$ ), $T_{\text {opt }}$ is the optimal temperature (in ${ }^{\circ} \mathrm{C}$ ) for microalgal/cyanobacterial growth and $\sigma$ is the standard deviation associated to the optimal temperature (in ${ }^{\circ} \mathrm{C}$ ).

Eqn (7) and (8) were used to establish a two-dimensional model, resulting in the following expression:

$$
\mu=\frac{\mu_{\mathrm{max}} I}{I_{\mathrm{opt}}} \mathrm{e}^{\left(1-\frac{I}{I_{\mathrm{opt}}}\right)} \mathrm{e}^{-\frac{\left(T-T_{\mathrm{opt}}\right)^{2}}{2 \sigma^{2}}}
$$

This expression was linearized (eqn (10)) and the parameters $\mu_{\text {max }}, I_{\text {opt }}, T_{\text {opt }}$ and $\sigma$ were determined by minimizing the sum of squared residuals using the Solver supplement of Microsoft Excel 2013.

$$
\ln \mu=\ln \mu_{\max }+\ln \frac{I}{I_{\mathrm{opt}}}+1-\frac{I}{I_{\mathrm{opt}}}-\frac{\left(T-T_{\mathrm{opt}}\right)^{2}}{2 \sigma^{2}}
$$

The quality of the model fits was evaluated by calculating the root mean squared error (RMSE), a performance index that measures the agreement between data obtained experimentally and predicted values:

$$
\mathrm{RMSE}=\sqrt{\frac{\sum(z-\hat{z})^{2}}{n}}
$$

where $z$ denotes the experimental values, $\hat{z}$ the predicted values by the model and $n$ the data size. 


\subsection{Statistical analysis}

For each parameter, the average and standard deviation were calculated. The statistical significance of the results was evaluated using the Student's paired $t$-test to investigate whether the differences between the studied cultures could be considered significant. This analysis was performed using the statistical software SPSS 22.0 (SPSS Inc., Chicago, IL, USA). Statistical tests were carried out at a significance level of 0.05 .

\section{Results and discussion}

\subsection{Influence of light supply and temperature on microalgal/cyanobacterial growth}

When growing autotrophically, microalgae and cyanobacteria strongly depend on light supply and temperature. ${ }^{8,9}$ These environmental factors influence growth dynamics (Fig. S1, ESI $\dagger$ ), including the specific growth rates and biomass productivities, and also nutrients uptake from the culture medium. Fig. 1 shows the effect of average daily light irradiance and temperature on specific growth rates of the microalgae $C$. vulgaris and P. subcapitata (A and B) and the cyanobacteria $S$. salina and $M$. aeruginosa (C and D). Maximum biomass concentrations and biomass productivities achieved in the exponential growth phase under these conditions are shown in Table 2. Specific growth rates determined for the studied microorganisms ranged from $0.0188 \pm 0.0033 \mathrm{~d}^{-1}$ (for $P$. subcapitata grown at $35{ }^{\circ} \mathrm{C}$ with an average daily light irradiance of $15 \mu \mathrm{E} \mathrm{m}^{-2} \mathrm{~s}^{-1}$ ) to $1.19 \pm 0.04 \mathrm{~d}^{-1}$ (for C. vulgaris grown at $25^{\circ} \mathrm{C}$ with an average daily light irradiance of $180 \mu \mathrm{E} \mathrm{m}^{-2} \mathrm{~s}^{-1}$ ). Regarding light supply, an increase in average daily light irradiance resulted in statistically higher $(p<0.05)$ specific growth rates. Several studies have already reported the increase of specific growth rates with increasing light supplies. ${ }^{12,35,36} \mathrm{~A}$ positive relationship between specific growth rates and average daily light irradiance is not surprising, since microalgal/ cyanobacterial growth is mainly autotrophic, requiring light as the major energy source. These results indicate that higher light supplies favoured the photosynthetic activity of the studied microorganisms, which was confirmed by the increase observed in average $\mathrm{pH}$ of the studied cultures: from $8.12 \pm 0.29$ (at $15 \mu \mathrm{E}$ $\mathrm{m}^{-2} \mathrm{~s}^{-1}$ ) to $8.76 \pm 1.03$ (at $180 \mu \mathrm{E} \mathrm{m}^{-2} \mathrm{~s}^{-1}$ ). The increase in $\mathrm{pH}$ of the culture medium is related to an increase in carbon uptake by microalgae or cyanobacteria and, hence, in photosynthetic activity. ${ }^{37}$ Culturing temperature also contributed to considerable changes in the specific growth rates of the studied microorganisms. Specific growth rates determined at $25{ }^{\circ} \mathrm{C}$ were statistically higher than those determined at $15(p<0.001)$ and $35{ }^{\circ} \mathrm{C}(p=0.001)$. However, no statistical differences $(p=0.087)$ were observed between specific growth rates determined at 15 and $35{ }^{\circ} \mathrm{C}$. These results indicate that the growth of the studied microorganisms in response to different temperatures may follow a normal distribution function, being the optimal culturing temperature approximately $25{ }^{\circ} \mathrm{C}$. Evidence that the optimal temperature for autotrophic microalgal/cyanobacterial growth is near $25^{\circ} \mathrm{C}$ was also given by the increase observed in $\mathrm{pH}$ and dissolved oxygen concentration at this temperature: for cultures performed at 15,25 and $35^{\circ} \mathrm{C}$ average $\mathrm{pH}$ of the culture medium was $8.32 \pm 0.43,8.91 \pm 0.91$ and $8.09 \pm 0.82$, respectively, whereas average dissolved oxygen concentration was 3.8 $\pm 1.1,6.5 \pm 0.4$ and $4.8 \pm 1.0 \mathrm{mg}_{\mathrm{O}_{2}} \mathrm{~L}^{-1}$, respectively. A similar behaviour was observed by James et al. ${ }^{38}$ when evaluating the effect of temperature on the growth and fatty acid and amino acid composition of two microalgae belonging to the genera Chlorella and Nannochloropsis. For temperatures ranging from 15 to $35^{\circ} \mathrm{C}$, an increase in specific growth rates was observed until $25{ }^{\circ} \mathrm{C}$, while for higher temperatures specific growth rates started decreasing. Similarly, when evaluating the optimum temperature and salinity conditions for the growth of Chlorella ellipsoidea and Nannochloris oculata, Cho et al. ${ }^{39}$ demonstrated that keeping a constant salinity of 10 , an increase in
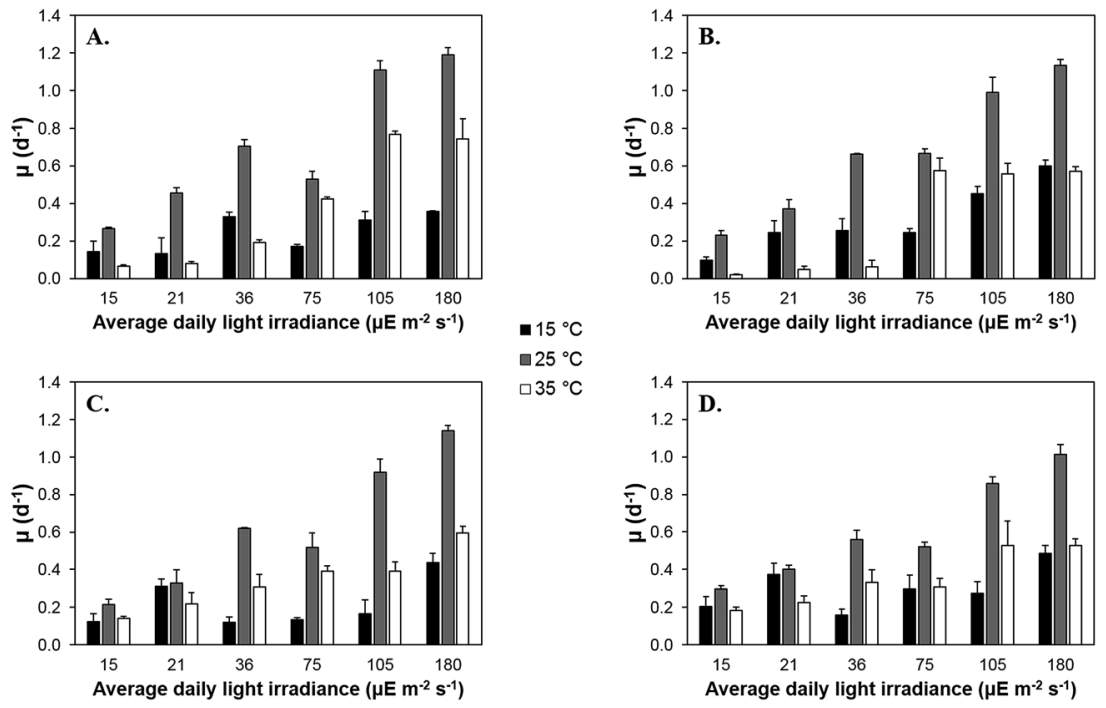

Fig. 1 Specific growth rates, in $\mathrm{d}^{-1}$, determined for C. vulgaris (A), P. subcapitata (B), S. salina (C) and M. aeruginosa (D) under different light and temperature conditions. Error bars correspond to the standard deviation of two independent experiments. 


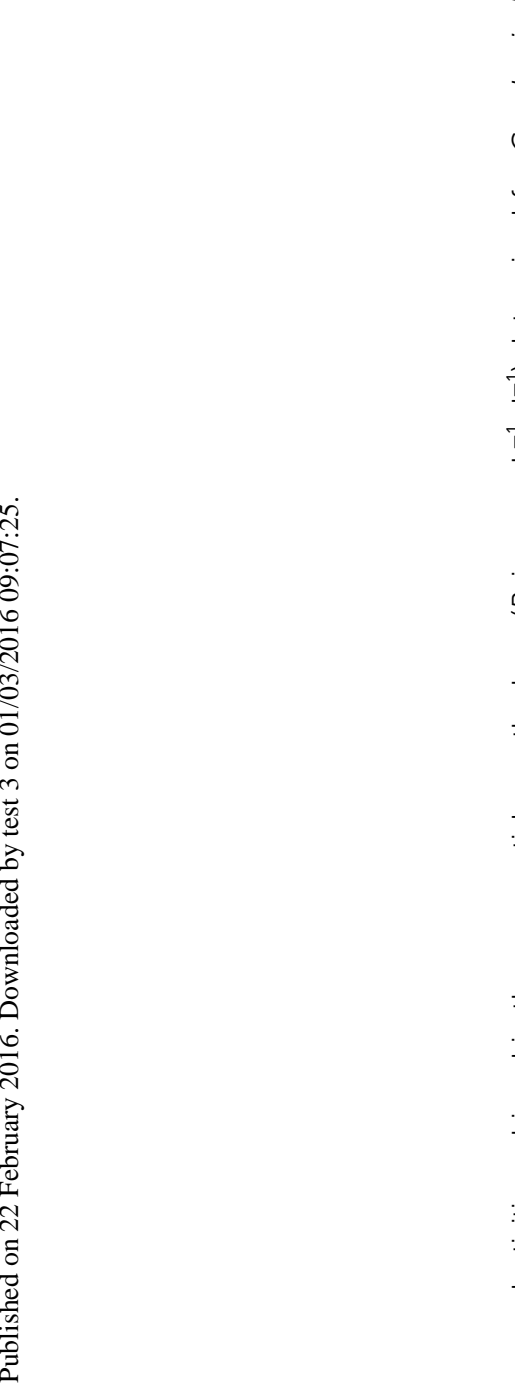

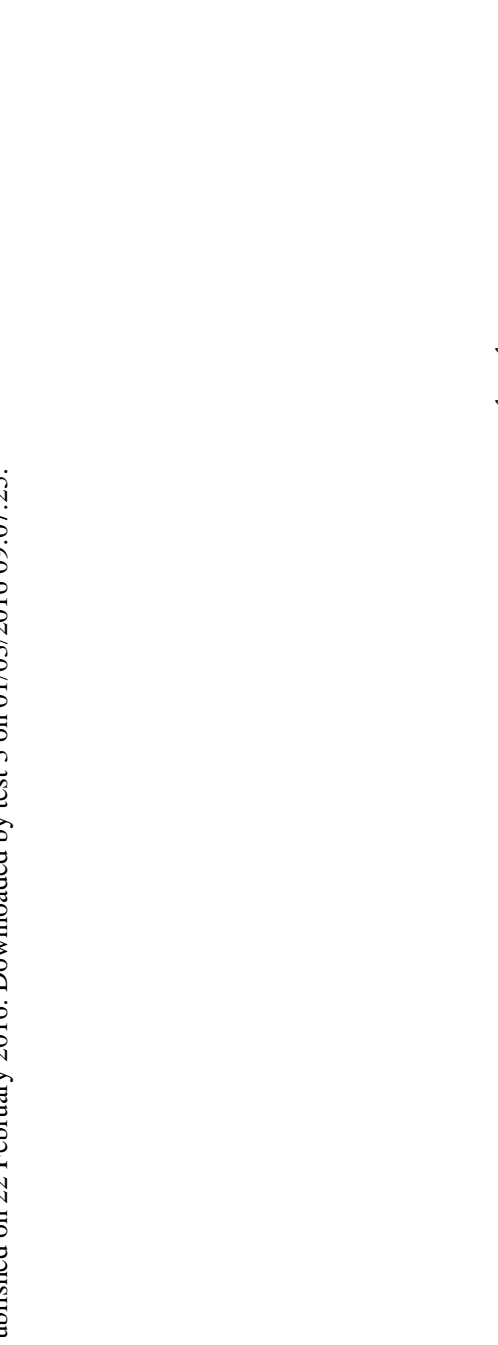

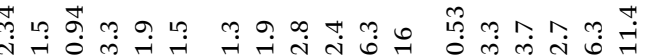
$H+H+H+H \quad H H+H+H \quad H H H+H+H$ 等

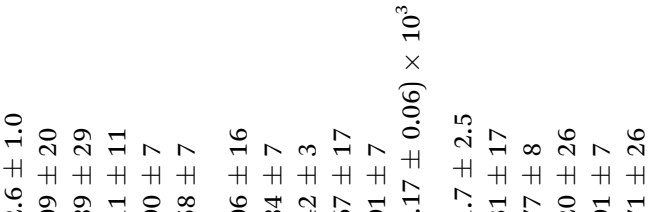

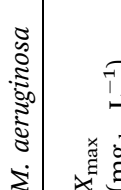

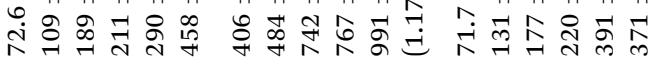

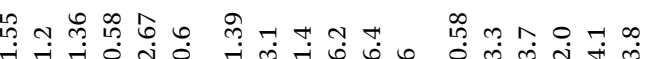
H H H H H H H H H H H H H H H H H

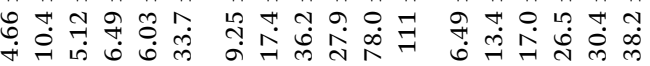

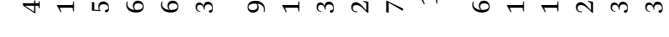
n

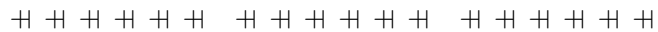

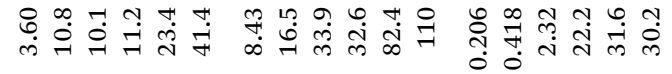

$\vec{m}$ 约 $H H H H H H+H+H H H$ H H H H

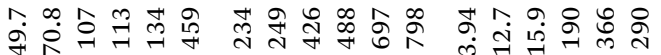

采 $H+H H H+H \quad H H H H H H \quad H H H H+H$

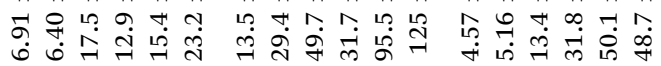

$\stackrel{3}{3} \stackrel{0}{\circ}$ F⿻ $H+H+H+H \quad H H H+H \quad H \quad H+H+H+H$

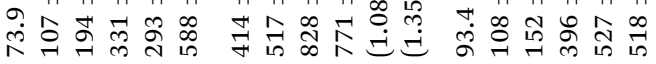


temperatures from 15 to $25{ }^{\circ} \mathrm{C}$ results in increased specific growth rates and, when temperature is increased to $30{ }^{\circ} \mathrm{C}$, specific growth rates tend to decrease. Average specific growth rates determined for Chlorella pyrenoidosa grown under a temperature range of 10 to $35{ }^{\circ} \mathrm{C}$ also increased until the temperature of $25{ }^{\circ} \mathrm{C}$, starting decreasing when culturing temperature was set at 30 and $35{ }^{\circ} \mathrm{C} .{ }^{\mathbf{4 0}}$

The influence of light supply and temperature on maximum biomass concentrations and biomass productivities was similar to the one observed for specific growth rates (Table 2). In this study maximum biomass concentration values ranged from $3.94 \pm 0.49$ (determined for $P$. subcapitata grown at $35^{\circ} \mathrm{C}$ with an average daily light irradiance of $\left.15 \mu \mathrm{E} \mathrm{m}^{-2} \mathrm{~s}^{-1}\right)$ to $(1.35 \pm$ $0.13) \times 10^{3} \mathrm{mg}_{\mathrm{dw}} \mathrm{L}^{-1}$ (determined for $C$. vulgaris grown at $25^{\circ} \mathrm{C}$ with an average daily light irradiance of $180 \mu \mathrm{E} \mathrm{m}^{-2} \mathrm{~s}^{-1}$ ). Minimum and maximum biomass productivities were determined for the same microorganisms in the same conditions: $0.206 \pm 0.111$ (for P. subcapitata grown at $35^{\circ} \mathrm{C}$ with an average daily light irradiance of $15 \mu \mathrm{E} \mathrm{m}^{-2} \mathrm{~s}^{-1}$ ) and $125 \pm 8 \mathrm{mg}_{\mathrm{dw}} \mathrm{L}^{-1}$ $\mathrm{d}^{-1}$ (for C. vulgaris grown at $25{ }^{\circ} \mathrm{C}$ with an average daily light irradiance of $180 \mu \mathrm{E} \mathrm{m} \mathrm{m}^{-2} \mathrm{~s}^{-1}$ ), respectively. As for specific growth rates, an increase in average daily light irradiance from 15 to $180 \mu \mathrm{E} \mathrm{m}^{-2} \mathrm{~s}^{-1}$ resulted in statistically higher $(p<0.05)$ maximum biomass concentrations and biomass productivities. Ugwu et al. ${ }^{41}$ demonstrated that an increase in light irradiance results in an increase in biomass productivities when growing Chlorella sorokiniana with average daily light irradiances ranging from 100 to $250 \mu \mathrm{E} \mathrm{m}^{-2} \mathrm{~s}^{-1}$. Regarding the effects of temperature, statistically higher $(p<0.05)$ maximum biomass concentrations and biomass productivities were determined for cultures grown at $25{ }^{\circ} \mathrm{C}$. In the case of cultures grown at 15 and $35{ }^{\circ} \mathrm{C}$, no statistical difference $(p>0.05)$ was observed in both maximum biomass concentrations and biomass productivities. Han et al. ${ }^{42}$ found that cultivation of C. pyrenoidosa at 22, 30 and $36{ }^{\circ} \mathrm{C}$ resulted in biomass productivities of $120 \pm 2,141 \pm 1$ and $125 \pm 2 \mathrm{mg} \mathrm{L}^{-1} \mathrm{~d}^{-1}$, respectively.

Comparing kinetic growth parameters determined for the studied microorganisms, it was possible to observe that $C$. vulgaris achieved the highest specific growth rate, maximum biomass concentration and biomass productivity when cultured at $25{ }^{\circ} \mathrm{C}$ under an average daily light irradiance of $180 \mu \mathrm{E} \mathrm{m}^{-2}$ $\mathrm{s}^{-1}$. In the same culturing conditions specific growth rates determined for $P$. subcapitata and $S$. salina were not statistically different $(p>0.05)$ from the one determined for $C$. vulgaris. In the case of $M$. aeruginosa, specific growth rate determined in these conditions was statistically lower $(p<0.05)$. Regarding maximum biomass concentrations and biomass productivities, values determined for $S$. salina and $M$. aeruginosa were not statistically different $(p>0.05)$ from those determined for $C$. vulgaris. However, statistically lower $(p<0.05)$ values were determined for P. subcapitata.

\subsection{Influence of light supply and temperature on nutrients removal}

To evaluate the influence of light supply and temperature on nitrogen and phosphorus removal, concentrations of these nutrients in the first and last day of culturing were determined and average removal rates and removal efficiencies were obtained. These results are shown in Table 3, for nitrogen, and Table 4, for phosphorus.

Regarding nitrogen removal, maximum average removal rate, $2.89 \pm 0.07 \mathrm{mg}_{\mathrm{N}} \mathrm{L}^{-1} \mathrm{~d}^{-1}$, was determined for $M$. aeruginosa grown at $25{ }^{\circ} \mathrm{C}$, with an average daily light irradiance of $36 \mu \mathrm{E}$ $\mathrm{m}^{-2} \mathrm{~s}^{-1}$. On the other hand, maximum nitrogen removal efficiency achieved was $100 \%$ (for C. vulgaris, P. subcapitata and $M$. aeruginosa grown at $25^{\circ} \mathrm{C}$ with an average daily light irradiance of $180 \mu \mathrm{E} \mathrm{m}^{-2} \mathrm{~s}^{-1}$ ). The influence of light supply and temperature in these variables was very similar. In the case of average daily light irradiance, higher values resulted in statistically higher $(p<0.05)$ removal rates and removal efficiencies. In the study performed by $\mathrm{Hu}$ et al. ${ }^{43}$ nitrate uptake rates determined for Synechococcus sp. grown in nitrate-contaminated groundwater increased proportionally to increasing average daily light irradiance up to $100 \mu \mathrm{E} \mathrm{m}^{-2} \mathrm{~s}^{-1}$. Regarding the effects of temperature, microalgal and cyanobacterial growth at $25{ }^{\circ} \mathrm{C}$ caused nitrogen removal rates and removal efficiencies statistically higher $(p<0.05)$ than those determined at 15 and $35^{\circ} \mathrm{C}$. The nitrogen removal rates and removal efficiencies were not statistically different $(p=0.146)$ between the extreme temperatures. Talbot and De la Noü $\mathrm{e}^{\mathbf{4 4}}$ demonstrated that cultivation of Phormidium bohneri in a secondary effluent from an activated sludge treatment plant at $30{ }^{\circ} \mathrm{C}$ for three days resulted in an effective removal of ammonia-nitrogen, whereas the same culture performed at $10{ }^{\circ} \mathrm{C}$ resulted in modest ammonianitrogen removal.

In the case of phosphorus removal, maximum average removal rate, $0.588 \pm 0.029 \mathrm{mg}_{\mathrm{P}} \mathrm{L}^{-1} \mathrm{~d}^{-1}$, was determined for $C$. vulgaris grown at $25^{\circ} \mathrm{C}$ with an average daily light irradiance of $180 \mu \mathrm{E} \mathrm{m}^{-2} \mathrm{~s}^{-1}$. Phosphorus removal efficiencies ranged from $1.13 \pm 0.03$ (for $M$. aeruginosa grown at $15{ }^{\circ} \mathrm{C}$, under the lowest average daily light irradiance) to $67.6 \pm 7.1 \%$ (for $C$. vulgaris grown at $25{ }^{\circ} \mathrm{C}$ with an average daily light irradiance of $180 \mu \mathrm{E}$ $\mathrm{m}^{-2} \mathrm{~s}^{-1}$ ). These values were lower than those determined for nitrate, indicating that phosphorus assimilation is slower than nitrate-nitrogen assimilation. Different studies have already reported higher removal efficiencies for nitrogen than for phosphorus. ${ }^{\mathbf{4 4 , 4 5}}$ The influence of light supply and temperature on phosphorus removal rates and removal efficiencies was similar to the one observed for nitrogen removal. In general, an increase in the light supply resulted in increased phosphorus removal rates and removal efficiencies. Statistically higher $(p<$ 0.05 ) removal rates and removal efficiencies were determined when light irradiance increased from 15 to $180 \mu \mathrm{E} \mathrm{m}^{-2} \mathrm{~s}^{-1}$. In the study performed by $\mathrm{Li}$ et al. ${ }^{\mathbf{4 6}}$ an increase in average daily light irradiance from 0 to $200 \mu \mathrm{E} \mathrm{m}^{-2} \mathrm{~s}^{-1}$ increased total phosphorus removal efficiencies from 65.8 to $87.0 \%$ (for Chlorella kessleri) and from 79.3 to $83.0 \%$ (for Chlorella protothecoides). The effects of temperature on phosphorus removal demonstrated that, in general, higher removal rates and removal efficiencies were obtained for cultures grown at $25{ }^{\circ} \mathrm{C}$. However, these values were not statistically different $(p>0.05)$ from those determined for the other studied temperatures. 


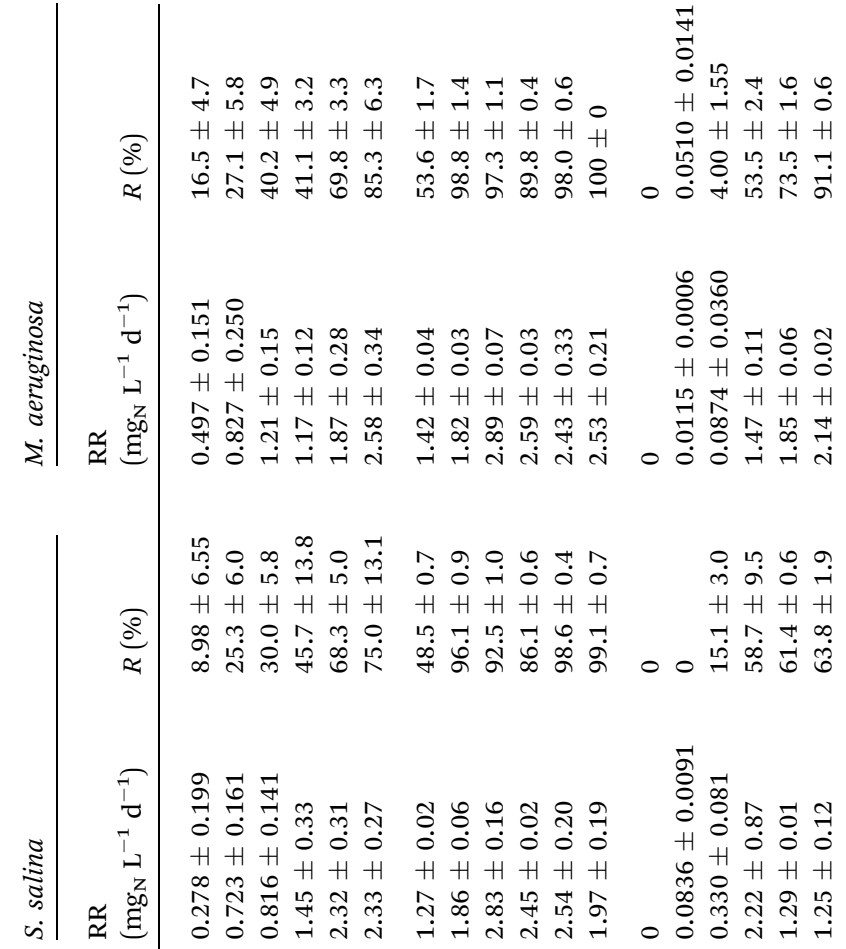

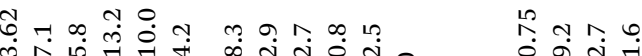

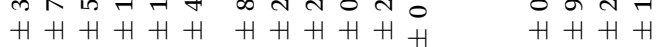

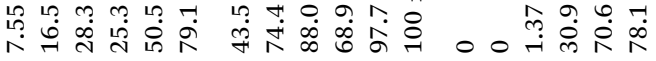

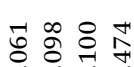

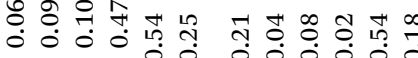

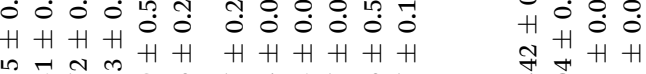

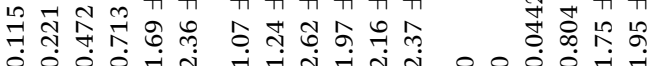

$\frac{c}{d}$

:

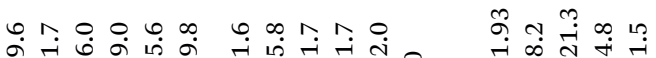
$H+H+H+H+H+H H+H$

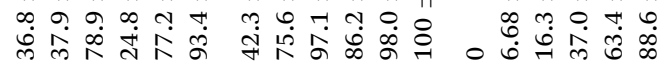

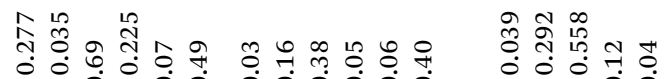

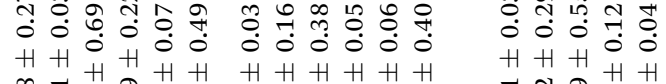

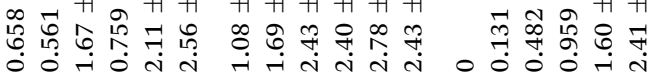


Table 5 Mass fractions of nitrogen $\left(\alpha_{N}\right.$, in $\left.g_{N} g_{d w}{ }^{-1}\right)$ and phosphorus $\left(\alpha_{P}\right.$, in $\left.g_{P} g_{d w}{ }^{-1}\right)$ incorporated in the biomass of $C$. vulgaris, P. subcapitata, $S$. salina and $M$. aeruginosa obtained through the mass balance performed for each nutrient ${ }^{a}$

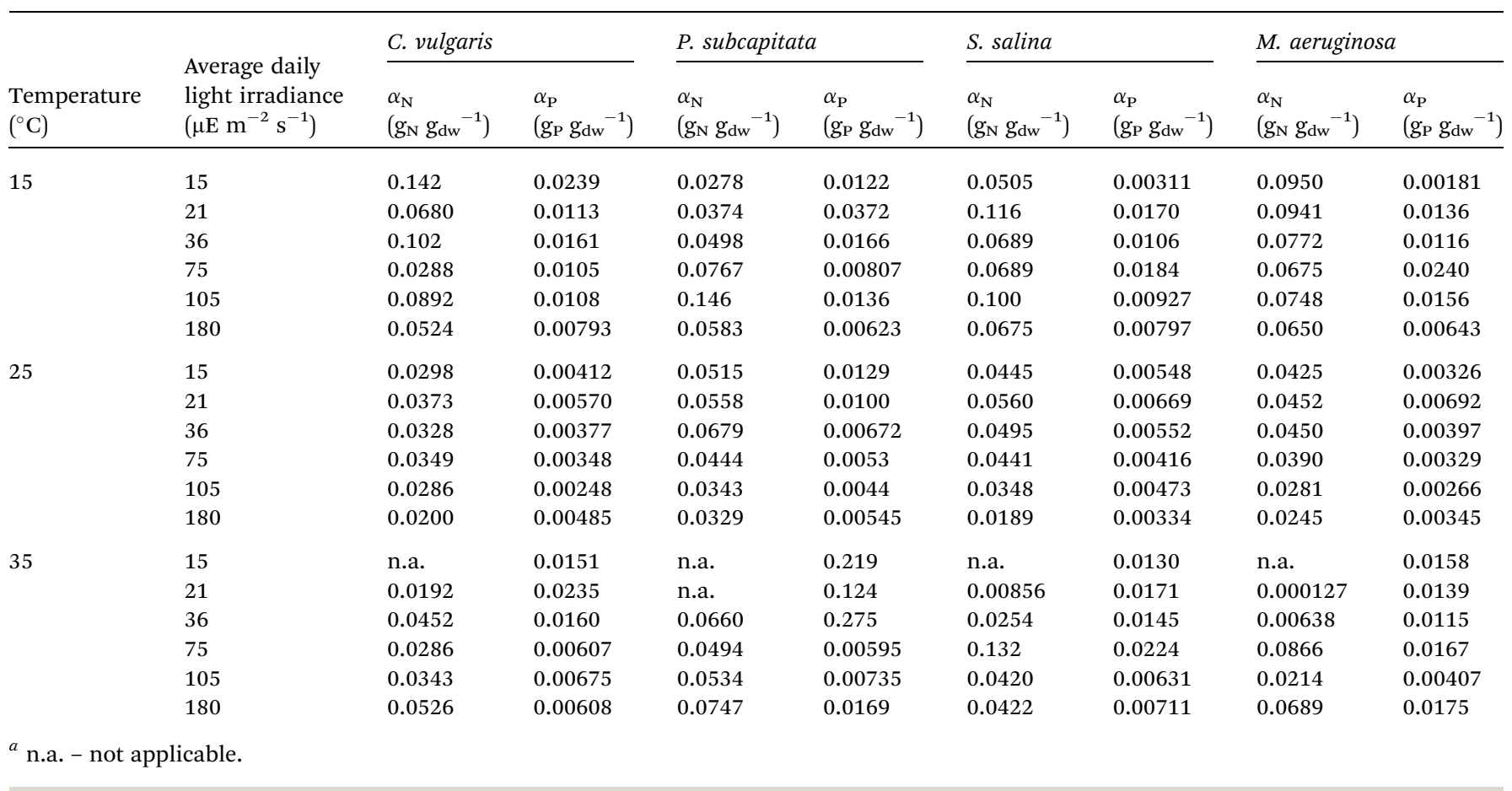

These results have shown that the influence of light supply and temperature on nitrogen and phosphorus removal is similar to the one observed for specific growth rates, maximum biomass concentrations and biomass productivities, paralleling photosynthetic activity. Microalgae and cyanobacteria require high amounts of nitrogen and phosphorus for proteins, which account for $40-60 \%$ of cell dry weight, nucleic acids and phospholipids synthesis, ${ }^{3}$ meaning that an increase in the photosynthetic activity may result in an increased assimilation of both nitrogen and phosphorus. Regarding the performance of the studied microorganisms in nitrogen and phosphorus removal, average removal rates and removal efficiencies were not statistically different $(p>0.05)$. Additionally, it was observed that the majority of cultures grown at $25{ }^{\circ} \mathrm{C}$, under the highest light supplies have effectively removed nitrogen. These results constitute important findings for the application of microalgal/ cyanobacterial cultures in the tertiary treatment step of wastewater treatment plants.

The mass balance written for nitrogen and phosphorus allowed the determination of the mass fractions of these nutrients in the biomass for each of the studied conditions (Table 5). Mass fractions of nitrogen and phosphorus were close to those reported in the typical composition of microalgal biomass $\left(\mathrm{CO}_{0.48} \mathrm{H}_{1.83} \mathrm{~N}_{0.11} \mathrm{P}_{0.01}\right): 6.59 \mathrm{~g}_{\mathrm{N}} \mathrm{g}_{\mathrm{dw}}{ }^{-1}$ and $1.33 \mathrm{~g}_{\mathrm{P}} \mathrm{g}_{\mathrm{dw}}{ }^{-1}$ for nitrogen and phosphorus, respectively. ${ }^{47}$ To have a better understanding about the effects of light and temperature on nitrogen and phosphorus contents on microalgal/cyanobacterial biomass, contour graphs relating these variables were obtained for the selected microorganisms (Fig. S2 and S3, ESI $\dagger$ ). Additionally, these parameters were analysed through multiple linear regression to evaluate which parameters significantly influence nitrogen and phosphorus mass fractions (Table S2, ESI $\dagger$ ). From these data, it is possible to conclude that the effect of light and temperature on the biochemical composition of microalgal/cyanobacterial biomass presented some differences between the studied microorganisms. These observations are in agreement with the study performed by Goldman, ${ }^{48}$ who concluded that the relationship between nitrogen contents and temperature may be species specific. Regarding nitrogen mass fractions, temperature appears as the most important factor influencing this parameter: (i) in the case of $C$. vulgaris and $S$. salina, an increase in temperature results in lower nitrogen mass fractions; (ii) in P. subcapitata, both light and temperature have not significantly influenced $(p>0.05)$ nitrogen mass fractions; and (iii) in $M$. aeruginosa, an increase in light and temperature results in lower nitrogen mass fractions and, on the other hand, the simultaneous increase in both light and temperature results in higher nitrogen mass fractions. As for nitrogen mass fractions, phosphorus mass fractions were also mainly influenced by temperature: (i) in C. vulgaris, an increase in temperature results in a decrease of phosphorus mass fractions, with the minimum value reached at approximately $25^{\circ} \mathrm{C}$, and the simultaneous increase in both light and temperature results in lower phosphorus mass fractions; (ii) in P. subcapitata, phosphorus mass fractions had a similar behaviour to the one described for nitrogen mass fractions in $M$. aeruginosa; and (iii) in $S$. salina and $M$. aeruginosa, an increase in temperature results in a decrease of phosphorus mass fractions, with the minimum value reached at approximately $25{ }^{\circ} \mathrm{C}$. These results indicate that environmental factors, such as light and 
temperature, not only affect the photosynthetic activity and biomass productivities, but also cell metabolism and, consequently, biochemical composition, as previously reported by $\mathrm{Hu} .^{9}$ The preponderance of temperature influence on nitrogen and phosphorus mass fractions behaviour suggests that these parameters were not strongly influenced by average daily light irradiance. Similar results were already reported by Mortensen et $a .^{49}$ In this study, nitrogen and phosphorus mass fractions determined for batch cultures of Chaetoceros gracilis grown with different light intensities at $28^{\circ} \mathrm{C}$ were not statistically different. The decrease of nitrogen and phosphorus mass fractions with increasing temperatures, which was common for the majority of the selected microorganisms has already been reported in the literature. In the study performed by $\mathrm{Fu}$ et $a .^{50}$ an increase in temperature from 20 to $24{ }^{\circ} \mathrm{C}$ resulted in a decrease in nitrogen and phosphorus mass fractions in the cyanobacteria Synechococcus sp. The U-shape response observed for some microorganisms has also been described in the literature. According to $\mathrm{Hu},{ }^{9}$ at temperatures below and above the optimal growth temperature, microalgae and cyanobacteria require higher amounts of nutrients, such as nitrogen and phosphorus, to achieve the same growth rates as those reported for optimal temperatures. Accordingly, nitrogen and phosphorus mass fractions tend to be lower at the optimal growth temperature, which was, in this study, around $25^{\circ} \mathrm{C}$.

\subsection{Optimal light and temperature conditions determined through mathematical modelling}

Optimal growth conditions (average daily light irradiance and temperature) for the selected microalgae and cyanobacteria were determined. For this, the model described by eqn (9) was
Table 6 Optimal growth conditions (average daily light irradiance and temperature) determined for $C$. vulgaris, $P$. subcapitata, S. salina and $M$. aeruginosa through mathematical modelling ${ }^{a}$

\begin{tabular}{lllll}
\hline & C. vulgaris & P. subcapitata & S. salina & M. aeruginosa \\
\hline$\mu_{\max }\left(\mathrm{d}^{-1}\right)$ & 1.30 & 1.21 & 1.14 & 1.02 \\
$I_{\mathrm{opt}}$ & 208 & 258 & 178 & 140 \\
$\left(\mu \mathrm{E} \mathrm{m} \mathrm{m}^{-2} \mathrm{~s}^{-1}\right)$ & & & & \\
$T_{\mathrm{opt}}\left({ }^{\circ} \mathrm{C}\right)$ & 25.4 & 23.7 & 26.4 & 25.6 \\
$\sigma\left({ }^{\circ} \mathrm{C}\right)$ & 7.0 & 7.0 & 7.2 & 8.2 \\
$\mathrm{RMSE}\left(\mathrm{d}^{-1}\right)$ & 0.294 & 0.198 & 0.319 & 0.255 \\
$n$ & 29 & 27 & 18 & 18 \\
& & & & \\
\multicolumn{7}{l}{ Model validation } \\
RMSE $\left(\mathrm{d}^{-1}\right)$ & 0.393 & 0.283 & 0.260 & 0.182 \\
$n$ & 9 & 9 & 6 & 6
\end{tabular}

${ }^{a}$ These values were obtained through application of the developed model regarding the effect of light irradiance and temperature on specific growth rates. $\mu_{\max }-$ maximum specific growth rate; $I_{\mathrm{opt}}-$ optimal average daily light irradiance value for microalgal/ cyanobacterial growth; $T_{\mathrm{opt}}$ - optimal temperature for microalgal/ cyanobacterial growth; $\sigma$ - standard deviation associated to the optimal temperature; RMSE - root mean squared error; $n$ - data size.

applied and surface graphs (Fig. 2) relating specific growth rates with average daily light irradiance and temperature were obtained. Analysis of Fig. 2 shows that an increase in average daily light irradiance results in increased specific growth rates, with optimal average daily light irradiances varying according to the studied species. Regarding the effect of temperature on specific growth rates, Fig. 2 evidences a similar behaviour between the studied microorganisms. When temperature increases from 15 to $35{ }^{\circ} \mathrm{C}$, specific growth rates tend to increase until

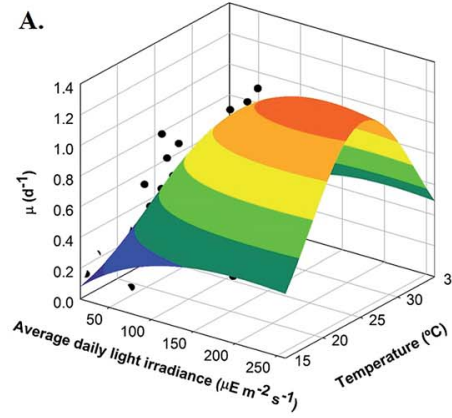

C.

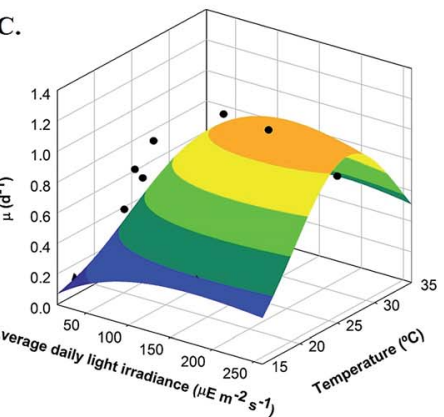

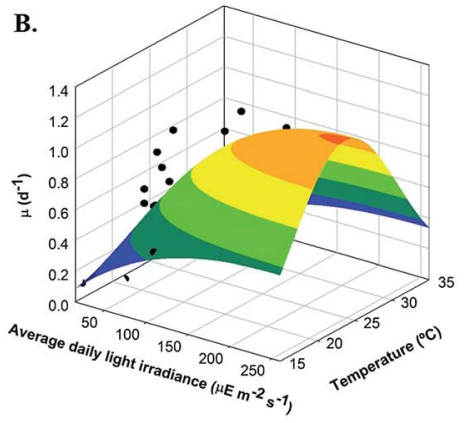

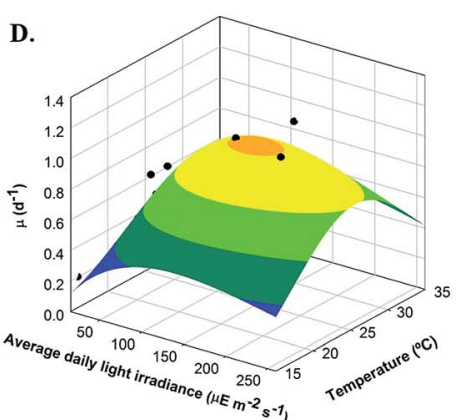

Fig. 2 Influence of average daily light irradiance and temperature on specific growth rates of C. vulgaris (A), P. subcapitata (B), S. salina (C) and M. aeruginosa (D). The dots correspond to the experimental data. The surface graphs were obtained through mathematical modelling. 
approximately $25{ }^{\circ} \mathrm{C}$, where specific growth rates start decreasing, reaching values close to those observed at $15{ }^{\circ} \mathrm{C}$.

Optimal average daily light irradiance and temperature determined through mathematical modelling for each microorganism are shown in Table 6. For determination of these parameters, it was assumed that maximum specific growth rates achieved by each microorganism could not be lower than the maximum specific growth rate value determined for each microalgal/cyanobacterial strain: 1.30, 1.13, 1.14 and $1.02 \mathrm{~d}^{-1}$ for C. vulgaris, $P$. subcapitata, S. salina and M. aeruginosa, respectively. Definition of this condition was based on the fact that each microalgal species usually presents a maximum specific growth rate, which is obtained under optimal growth conditions. ${ }^{51}$ From Table 6, it is possible to observe that optimal temperatures determined for the studied microorganisms were very similar. $T_{\text {opt }}$ values determined through mathematical modelling for C. vulgaris, P. subcapitata, S. salina and M. aeruginosa were 25.4, 23.7, 26.4 and $25.6{ }^{\circ} \mathrm{C}$, respectively. These values were slightly lower than optimal temperature determined for $C$. vulgaris growth in the study performed by Dauta et al. ${ }^{34}$ In this study, for a maximum specific growth rate of $1.30 \mathrm{~d}^{-1}$, optimal temperature determined for C. vulgaris was $30^{\circ} \mathrm{C}$. However, other studies reported optimal growth temperatures close to $25{ }^{\circ} \mathrm{C}$. In the study performed by Claquin et al., ${ }^{52}$ average optimal temperature determined for eight species of marine microalgae (Thalassiosira pseudonana, Skeletonema marinoi, Pseudo-nitzschia fraudulenta, Emiliania huxleyi, Isochrysis galbana, Isochrysis aff. galbana, Pavlova lutheri and Lepidodinium chlorophorum) was $23.7 \pm 3.1{ }^{\circ} \mathrm{C}$, corresponding to a maximum specific growth rate of $1.27 \pm 0.27 \mathrm{~d}^{-1}$. Yang et al. ${ }^{40}$ demonstrated that $C$. vulgaris can grow normally in the temperature range of 5 to $30{ }^{\circ} \mathrm{C}$, being optimal growth temperature $25{ }^{\circ} \mathrm{C}$. Through mathematical modelling, Aleya et al. ${ }^{53}$ determined an optimal growth temperature for Chlorella minutissima of $28{ }^{\circ} \mathrm{C}$, corresponding to a maximum specific growth rate of $0.7 \mathrm{~d}^{-1}$. Regarding optimal average daily light irradiances determined using this model, Table 6 shows that $I_{\text {opt }}$ values differ according to microalgal/cyanobacterial species, being 208, 258, 178 and $140 \mu \mathrm{E} \mathrm{m}^{-2} \mathrm{~s}^{-1}$ for C. vulgaris, P. subcapitata, S. salina and M. aeruginosa, respectively. Similar orders of magnitude have already been reported in the literature for several microalgae and cyanobacteria. Optimal average daily light irradiance values determined by Dauta et al. ${ }^{34}$ for C. vulgaris, Fragilaria crotonensis, Staurastrum pingue and Synechocystis minima ranged from 78 to $169 \mu \mathrm{E} \mathrm{m}^{-2} \mathrm{~s}^{-1}$. On the other hand, optimal average daily light irradiances determined for Selenastrum minutum, Coelastrum microporum $f$. astroidea and Cosmarium subprotumidum ranged from 250 to $263 \mu \mathrm{E} \mathrm{m} \mathrm{m}^{-2}$ $\mathrm{s}^{-1} \cdot{ }^{51}$ However, optimal average daily light irradiance determined for $C$. vulgaris and P. subcapitata surpassed the range of values assessed in this study, meaning that optimal growth of these microalgae is expected to occur for an average daily light irradiance of 208 and $258 \mu \mathrm{E} \mathrm{m}^{-2} \mathrm{~s}^{-1}$, respectively. Although these results were not validated experimentally, it is possible to propose that the established models can be correctly applied to describe the response of specific growth rates of the studied microorganisms to light and temperature. In fact, optimal light and temperature conditions determined are in accordance with the ones already reported in the literature. Additionally, the low RMSE values determined (ranging from 0.198 to $0.319 \mathrm{~d}^{-1}$ ) indicate that these models correctly fit to the experimental data. Nevertheless, the current models were validated by evaluating the RMSE values obtained between specific growth rates determined by these models and a validation data set composed by specific growth rates determined in different light and temperature conditions (Table S3, ESI $\dagger$ ). With the current models, RMSE values determined for C. vulgaris, P. subcapitata, $S$. salina and M. aeruginosa were $0.294,0.198,0.319$ and 0.255 $\mathrm{d}^{-1}$, respectively. On the other hand, RMSE determined through application of this model to data obtained from other studies (validation data set) was $0.393,0.283,0.260$ and $0.182 \mathrm{~d}^{-1}$, respectively. These results indicate that the developed model can be correctly applied to the studied microorganisms grown under light and temperature conditions within the range of those reported in this study. Additionally, in this study specific mathematical models were determined for different microalgal/ cyanobacterial species. Determination of an adequate model that describes microalgal/cyanobacterial growth in relation to light supply and temperature may result in several savings, especially in the optimization of cultivation conditions.

\section{Conclusions}

In this study, the effects of average daily light irradiance and temperature on microalgal/cyanobacterial growth and nutrients (nitrogen and phosphorus) uptake was evaluated. The results have shown that increased light supplies favour both biomass productivities and nutrients removal. Regarding the temperature effect, it was observed that the studied microorganisms presented higher photosynthetic activity at $25{ }^{\circ} \mathrm{C}$. Among the studied microorganisms, C. vulgaris, $S$. salina and $M$. aeruginosa have shown to be the most effective in biomass production. Development of a mathematical model able to describe the behaviour of specific growth rates in response to average daily light irradiance and temperature allowed the determination of optimal light and temperature conditions for the selected microalgae and cyanobacteria. This mathematical approach can be correctly applied to the selected microorganisms under light and temperature conditions within the range of those used in this study, providing the rapid determination of optimal growth conditions and reducing the time and costs associated to the optimization of culture parameters.

\section{Acknowledgements}

This work was financially supported by: Project UID/EQU/ 00511/2013-LEPABE, by the FCT/MEC with national funds and when applicable co-funded by FEDER in the scope of the P2020 Partnership Agreement; Project NORTE-07-0124-FEDER-000025 - RL2_Environment \& Health, by FEDER funds through Programa Operacional Factores de Competitividade - COMPETE, by the Programa Operacional do Norte (ON2) program and by national funds through FCT - Fundação para a Ciência e a Tecnologia; SFRH/BD/88799/2012 and SFRH/BPD/66721/2009. 
The authors also acknowledge CIIMAR (Centre of Marine and Environmental Research of the University of Porto), for providing the cyanobacteria Synechocystis salina LEGE 06079 and Microcystis aeruginosa LEGE 91344.

\section{References}

1 D. Tang, W. Han, P. Li, X. Miao and J. Zhong, Bioresour. Technol., 2011, 102, 3071-3076.

2 I. Rawat, R. Ranjith Kumar, T. Mutanda and F. Bux, Appl. Energy, 2011, 88, 3411-3424.

3 A. M. Silva-Benavides and G. Torzillo, J. Appl. Phycol., 2012, 24, 267-276.

4 L. Brennan and P. Owende, Renewable Sustainable Energy Rev., 2010, 14, 557-577.

$5 \mathrm{Q} . \mathrm{Hu}$, in Handbook of microalgal culture: biotechnology and applied phycology, ed. A. Richmond, Blackwell Science Ltd, Oxford, UK, 1st edn, 2004, ch. 12, pp. 268-271.

6 A. Parmar, N. K. Singh, A. Pandey, E. Gnansounou and D. Madamwar, Bioresour. Technol., 2011, 102, 10163-10172.

7 S. Singh, B. Kate and U. Banerjee, Crit. Rev. Biotechnol., 2005, 25, 73-95.

8 L. Barsanti and P. Gualtieri, Algae - Anatomy, Biochemistry and Biotechnology, CRC Press, USA, 2nd edn, 2006.

9 Q. $\mathrm{Hu}$, in Handbook of microalgal culture: biotechnology and applied phycology, ed. A. Richmond, Blackwell Science Ltd, Oxford, UK, 1st edn, 2004, ch. 5, pp. 83-94.

10 A. Kumar, S. Ergas, X. Yuan, A. Sahu, Q. Zhang, J. Dewulf, F. X. Malcata and H. Van Langenhove, Trends Biotechnol., 2010, 28, 371-380.

11 H.-W. Y. Yen, I.-C. Hu, C.-Y. Chen and J.-S. Chang, in Biofuels from Algae, ed. A. Pandey, D.-J. Lee, Y. Chisti and C. R. Soccol, Elsevier, USA, 1st edn, 2013, ch. 2, pp. 23-46.

12 J. G. Sánchez, J. S. Pérez, F. G. Camacho, J. F. Sevilla and E. M. Grima, Biotechnol. Tech., 1996, 10, 329-334.

13 S. Chinnasamy, B. Ramakrishnan, A. Bhatnagar and K. C. Das, Int. J. Mol. Sci., 2009, 10, 518-532.

14 C. J. McLarnon-Riches, C. E. Rolph, D. L. Greenway and P. K. Robinson, Phytochemistry, 1998, 49, 1241-1247.

15 R. Philippis and M. Vincenzini, FEMS Microbiol. Rev., 1998, 22, 151-175.

16 B. D. Wahlen, R. M. Willis and L. C. Seefeldt, Bioresour. Technol., 2011, 102, 2724-2730.

17 R. W. Eppley, Fish. Bull., 1972, 70, 1063-1085.

18 R. A. Parker, J. Fish. Res. Board Can., 1974, 31, 1550-1552.

19 J. Peeters and P. Eilers, Hydrobiol. Bull., 1978, 12, 134-136.

20 J. H. Steele, in Chemical reactor theory, ed. L. Lapidus and N. R. Amunson, Prentice-Hall, Englewood Cliffs, New Jersey, 1977, vol. 7, pp. 405-483.

21 O. Bernard and B. Rémond, Bioresour. Technol., 2012, 123, 520-527.

22 A. P. Carvalho and F. X. Malcata, Biotechnol. Prog., 2003, 19, 1128-1135.

23 H. Haario, L. Kalachev and M. Laine, Bull. Math. Biol., 2009, 71, 1626-1648.
24 OECD (Organisation for Economic Co-operation and Development), Freshwater alga and cyanobacteria, growth inhibition test, 2011.

25 L. Wang, M. Min, Y. Li, P. Chen, Y. Chen, Y. Liu, Y. Wang and R. Ruan, Appl. Biochem. Biotechnol., 2010, 162, 1174-1186.

26 A. K. Pegallapati and N. Nirmalakhandan, Renewable Energy, 2013, 56, 129-135.

27 A. Gonçalves, M. Simões and J. Pires, Energy Convers. Manage., 2014, 85, 530-536.

28 P. Feng, Z. Deng, L. Fan and Z. Hu, J. Biosci. Bioeng., 2012, 114, 405-410.

29 E. Jacob-Lopes, C. H. G. Scoparo, L. M. C. F. Lacerda and T. T. Franco, Chem. Eng. Process., 2009, 48, 306-310.

30 Y. Collos, F. Mornet, A. Sciandra, N. Waser, A. Larson and P. J. Harrison, J. Appl. Phycol., 1999, 11, 179-184.

31 B. Lee, S. Y. Park, Y. S. Heo, S. S. Yea and D.-E. Kim, Bull. Korean Chem. Soc., 2009, 30, 2485-2488.

32 M. Wang, W. C. Kuo-Dahab, S. Dolan and C. Park, Bioresour. Technol., 2014, 154, 131-137.

33 J. M. Lee, Biochemical engineering, Prentice Hall, Englewood Cliffs, New Jersey, 1st edn, 1992.

34 A. Dauta, J. Devaux, F. Piquemal and L. Boumnich, Hydrobiologia, 1990, 207, 221-226.

35 D. Schlesinger, L. Molot and B. Shuter, Can. J. Fish. Aquat. Sci., 1981, 38, 1052-1058.

36 C. Sorokin and R. W. Krauss, Plant Physiol., 1958, 33, 109113.

37 J. Uusitalo, Sci. Mar., 1996, 60, 129-134.

38 C. James, S. Al-Hinty and A. Salman, Aquaculture, 1989, 77, 337-351.

39 S. H. Cho, S.-C. Ji, S. B. Hur, J. Bae, I.-S. Park and Y.-C. Song, Fish. Sci., 2007, 73, 1050-1056.

40 G.-J. Yang, Z.-Q. Luan, X.-H. Zhou and Y. Mei, J. Jap. Soc. Math. Phys. Fish. Sci., 2010, 8, 68-74.

41 C. Ugwu, H. Aoyagi and H. Uchiyama, Photosynthetica, 2007, 45, 309-311.

42 F. Han, W. Wang, Y. Li, G. Shen, M. Wan and J. Wang, Bioresour. Technol., 2013, 132, 182-189.

43 Q. Hu, P. Westerhoff and W. Vermaas, Appl. Environ. Microbiol., 2000, 66, 133-139.

44 P. Talbot and J. De la Noüe, Water Res., 1993, 27, 153-159.

45 K. Lee and C.-G. Lee, Biotechnol. Bioprocess Eng., 2001, 6, 194-199.

46 Y. Li, W. Zhou, B. Hu, M. Min, P. Chen and R. R. Ruan, Biotechnol. Bioeng., 2012, 109, 2222-2229.

47 Y. Chisti, Biotechnol. Adv., 2007, 25, 294-306.

48 J. C. Goldman, Limnol. Oceanogr., 1977, 22, 932-936.

49 S. H. Mortensen, K. Y. Børsheim, J. Rainuzzo and G. Knutsen, J. Exp. Mar. Biol. Ecol., 1988, 122, 173-185.

50 F.-X. Fu, M. E. Warner, Y. Zhang, Y. Feng and D. A. Hutchins, J. Phycol., 2007, 43, 485-496.

51 R. Bouterfas, M. Belkoura and A. Dauta, Hydrobiologia, 2002, 489, 207-217.

52 P. Claquin, I. Probert, S. Lefebvre and B. Veron, Aquat. Microb. Ecol., 2008, 51, 1-11.

53 L. Aleya, A. Dauta and C. S. Reynolds, Eur. J. Protist., 2011, 47, 239-244. 